\title{
Pediatric interventional radiology work force survey summary
}

\author{
Manrita K. Sidhu • Charles A. James • \\ Roger K. Harned II • Bairbre L. Connolly • \\ Josée Dubois • Frank P. Morello • Robin Kaye • \\ Nadia J. Siddiqui • Paula K. Roberson • Kristy D. Seidel
}

Published online: 3 January 2007

(C) Springer-Verlag 2007

The online version of the original article can be found at http://dx.doi.org/ $10.1007 / \mathrm{s} 00247-006-0354-4$ and is accessible for authorized users.

\section{K. Sidhu $(\bowtie)$}

Seattle Radiologists, Department of Radiology,

Children's Hospital and Regional Medical Center,

University of Washington School of Medicine,

4800 Sand Point Way NE, Seattle, WA 98105, USA

e-mail: manrita.sidhu@seattlechildrens.org

C. A. James

Department of Radiology, University of Arkansas

for Medical Sciences, Arkansas Children's Hospital,

Little Rock, AR, USA

R. K. Harned II

Mae Boettcher Center for Pediatric Imaging,

The Children's Hospital,

Denver, CO, USA

B. L. Connolly

Image Guided Therapy, Diagnostic Imaging,

The Hospital for Sick Children,

Ontario, Canada

J. Dubois

Department of Radiology, Hôpital Ste-Justine,

Montréal, Canada

F. P. Morello

Department of Radiology, Children's Mercy Hospital,

Kansas, MO, USA

R. Kaye

Department of Radiology, Children's Hospital of Wisconsin,

Milwaukee, WI, USA

N. J. Siddiqui • P. K. Roberson

Biostatistics, University of Arkansas for Medical Sciences,

Little Rock, AR, USA

K. D. Seidel

Office of Biostatistical Services,

Children's Hospital and Regional Medical Center,

Seattle, WA, USA

\section{Pediatr Radiol (2007) 37:113-115}

Page 114, right column, question "Do you have an IR clinic?...": the answer should begin "Daily, $8 \% \ldots$... not "Daily, $80 \%$...". 